\title{
3 Research Square

\section{Unveiling The Potential Tolerance And Physiological Responses Mechanisms of Wheat (Ningmai 16) After Exposure to Nickel In a Soil-plant System}

\section{Gehui Wang}

East China University of Science and Technology

Muhammad Tariq

East China University of Science and Technology

Fang Liu

Shanghai Academy of Environmental Sciences

Qinran Xiao

East China University of Science and Technology

Cheng Peng

East China University of Science and Technology

Wei Zhang ( $\nabla$ wzhang@ecust.edu.cn )

East China University of Science and Technology

Jie Yang

Shanghai Academy of Environmental Sciences

\section{Research Article}

Keywords: Nickel, Soil-plant system, Accumulation, Gene expression, TEM observation

Posted Date: November 22nd, 2021

DOI: https://doi.org/10.21203/rs.3.rs-1038250/v1

License: (c) (1) This work is licensed under a Creative Commons Attribution 4.0 International License. Read Full License 


\section{Abstract}

Nickel (Ni) accumulation in soils could lead to critical risks to plants, animals and humans. This study aims to unveil the adverse impacts of $\mathrm{Ni}$ on wheat Ningmai 16 and toxicity tolerance mechanisms. Lipid peroxidation was significantly facilitated under high Ni stress, mainly reflecting the notable accumulation of malondialdehyde followed by the increase in glutathione-S-transferase (GST) activities. High Ni contamination caused the decrease in chlorophyll content, with the remarkable inhibition of root activity. Transmission electron microscopy (TEM) micrographs further confirmed the toxicity of $\mathrm{Ni}$ and provided significant supporting evidence for the accumulation and localisation of $\mathrm{Ni}$ in wheat. The mechanisms adopted in alleviating the oxidative damages induced by Ni were revealed by increasing the soluble sugar and proline content, and inducing the GST related gene expression. Additionally, the cell-wall thickening and vacuole compartmentation were also produced in wheat for improving the tolerance of Ni. Finally, most of biochemical parameters indicated a clearly positive or negative relationship with the available $\mathrm{Ni}$ contents, and they are proved as good biomarkers to predict the bioavailability of $\mathrm{Ni}$ in a soil-wheat system. We believe that our concluding findings would open a new window for a deeper understanding of ecological risks of an often-underestimated element $\mathrm{Ni}$ in future endeavors.

\section{Introduction}

Heavy metals contamination, especially the presence of heavy metals in soils has become a major threat to the world's environmental sustainability due to their complex removal/ remediation by conventional techniques (Chandrasekhar et al., 2019). Among different kinds of heavy metals contamination, the soil pollution caused by the presence of $\mathrm{Ni}$ is a very serious issue due to its wide application in metallurgical and electroplating industries (Zhao et al., 2019; Soares et al., 2016; Nkongolo et al., 2018). Although, Ni has been considered as an essential element for soil plants, microorganisms and animals. The presence of excessive Ni entering into soil environment can inevitably bring a series of negative effects on soil organisms and lead to significant hazards to natural ecosystems (Zhao et al., 2019; Xia et al., 2018; Wang et al., 2020). Additionally, Ni has the tendency of frequent movement and migration in soils, which makes it easier to transmit along the food chain and ultimately endanger human health (Wang et al., 2020). It has been proved in the literatures that human suffering from eczema, allergic inflammation, dry conjunctiva, lung cancer and other diseases, are related to high intake of $\mathrm{Ni}$ (He et al., 2011; Zhao et al., 2019).

The phytotoxicity of $\mathrm{Ni}$ has been reported frequently over the past few decades. Growth development and vitality level of plant roots would firstly be destroyed due to the toxicity of Ni. Moreover, 2,3,5triphenyltetrazolium chloride (TTC) reduction content is considered as an important indicator of vitality level of the roots (Seregin and Kozhevnikova, 2006). In addition, it is well known that high concentrations of Ni can lead to biological complication in the growth, mineral nutrition, sugar transport, water relation, photosynthesis, and respiration of plants (Shaw et al., 2004; Seregin and Kozhevnikova, 2006; Chen et al., 2010). Excessive Ni toxicity can also cause the viration of cellular structure, and directly disturb the normal performance of cellular organelles including chloroplast, mitochondrial, nucleus, large vacuole 
ribosomes, etc (Chandrasekhar et al., 2019; Sorrentino et al., 2018, Chandra et al., 2010). Numerous literatures have revealed that the generating of reactive oxygen species (ROS) and malonaldehyde (MDA) in plant cells and tissues is recognized as a signal of lipid peroxidation (Soares et al., 2016; Chandrasekhar et al., 2019; Zhao et al., 2019; Rizwan et al., 2018). However, glutathione S-transferase (GST) as a part of defense mechanism can fight against ROS toxicity, which exists in most organisms and regulates important pathways of cell signaling, detoxification and biosynthesis (Yang and Zhang, 2015; Zhao et al., 2019). GST family protein gene has also been reported with respect to metals transport or resistance (Nkongolo et al., 2018; Zhao et al., 2019), while few studies have been conducted to investigate GST and related gene in wheat under the Ni stress.

It is very meaningful to focus on the toxic effects of heavy metals and understand the complex plantmediated defence mechanisms. For example, some tolerant species with hyperaccumulation potentials for heavy metals can be used for soil rehabilitation (Chandra et al., 2010; Ali et al., 2013). For some heavy metal-sensitive plants, they can be regarded as sensitive biological indicators to evaluate heavy metals pollution and provide early warning for the environment (Norouzi et al., 2015). Besides, compared with some developed countries such as United States, United Kingdom, and Netherlands, ecological risk assessment started late in China (Zheng et al., 2018). There is no available risk-based ecological soil screening levels in China to protect the agricultural soil and ensure the safety of agricultural products. Therefore, establishing the ecological screening value is an urgent and critical task at present (Zheng et al., 2018). The overall research work should be based on a large amount of ecotoxicological data along with the exploration of the toxic impacts of $\mathrm{Ni}$ on wheat in a soil system.

There are few research works involving in the wheat with respect to Ni-contaminated soil. The toxicity responses and tolerance mechanisms of wheat exposed to Ni-contaminated soil were not clearly reported. Moreover, it is very important to study the accumulation and transportation of heavy metals in edible wheat to ensure food safety and human health. Wheat is widely cultivated in all over the world because of its strong adaptability to environmental changes. It shows the great significance to systematically explore the toxicity responses and tolerance mechanisms of wheat exposed to $\mathrm{Ni}$ contaminated soil. Additionally, the establishment of terrestrial ecosystem toxicology database along with the establishment of more practical regional soil environmental quality standards in China urgently needs these fundamental data related to the ecotoxicity. In our present conducted study, we chose an excellent variety of wheat "Ningmai 16 " as the experimental material. It is widly distributed in the Yangtze River Delta. We have focused on the differences of bioconcentration and translocation factors of $\mathrm{Ni}$ in wheat roots and shoots in the current research work. Transmission electron microscopy (TEM) was employed to determine ultrastructural changes and Ni intra-cellular distribution in wheat cells. Moreover, the implication of Ningmai 16 for Ni tolerance has also been explored in detail, along with physiological parameters such as chlorophyll content, TTC reduction content, proline and MDA content. Besides, the Niresistance related gene GST and their expression products (GST enzyme content) were investigated to elucidate the tolerance mechanisms of wheat at a gentic level. Additionally, we try to establish a significant relationship between these physiological parameters and $\mathrm{Ni}$ contents by using different 
extractants such as $\mathrm{CaCl}_{2}, \mathrm{HNO}_{3}$, and EDTA. We believe that our current study would deeply revealed the tolerance mechanisms and physiological responses of Ningmai 16 after exposure to Ni. The present study will open the new avenues for deeper insights into Ni threat to the health of human beings followed by the availability of basic data support for the establishment of ecological risk assessment system of heavy metals contaminated soil.

\section{Materials And Methods}

\subsection{Chemicals and plant materials}

Analytical grade of Nickel (II) nitrate hexahydrate $\left[\mathrm{Ni}\left(\mathrm{NO}_{3}\right)_{2} \cdot 6 \mathrm{H}_{2} \mathrm{O}\right]$ as soil poisoning reagent was used in our experiments. All analytical reagents were purchased from Sinopharm Chemical Reagent Co., Ltd. Seeds of "Ningmai 16" were bought from Jiangsu Academy of Agricultural Sciences.

\subsection{Soil preparation and plant cultivation}

Soil samples were collected from uncontaminated top layer $(0 \sim 20 \mathrm{~cm})$ farmland soil at Fengxian district, Shanghai, China. All collected soil was naturally air-dried, grounded and sieved (2-mm) for Ni poisoning. Physicochemical properties of soil were characterized as shown in Table S1 (Supplementary Material). Different concentrations of $\mathrm{Ni}\left(\mathrm{NO}_{3}\right)_{2} \cdot 6 \mathrm{H}_{2} \mathrm{O}$ solution were added to $1.0 \mathrm{~kg}$ dry soil, and then mixed thoroughly obtaining artificially Ni-contaminated soil. The concentrations of $\mathrm{Ni}$ in soils were spiked as 0 , $100,200,400,800$, and $1200 \mathrm{mg} / \mathrm{kg}$, respectively, abbreviated as CK-Ni, $100-\mathrm{Ni}, 200-\mathrm{Ni}, 400-\mathrm{Ni}, 800-\mathrm{Ni}$, and 1200-Ni. Three parallel groups were set up for each treatment. The mixed soil was kept natural aging for 30 days before cultivation of Ningmai 16.

Healthy seeds with the same size were chosen for culture. Firstly, the seeds were disinfected with $5 \%$ hydrogen peroxide and soaked in deionized water for at least two hours, then incubated at $20^{\circ} \mathrm{C}$ in a dark environment for 48 60 hours to germinat. Six germinated seeds were selected and transplanted into each processing group. The environmental temperature was kept at $18 \sim 22^{\circ} \mathrm{C}$, and the humidity was maintained at about $70 \%$ of the field capacity by watering once a day. All test groups were poured $1 / 3$ Hoagland nutrient solution once a week. In the culture cycle, the samples of shoots and roots were collected regularly for experimental analysis.

\subsection{Determination of $\mathrm{Ni}$ in wheat and soil}

Fresh root and shoot samples were oven dried for $15 \mathrm{~min}$ at $105^{\circ} \mathrm{C}$ followed by drying at $70^{\circ} \mathrm{C}$ overnight, then these were crushed followed by the mixing. The total contents of $\mathrm{Ni}$ in plant samples were determined as follows: $0.5 \mathrm{~g}$ dry matter was digested with $\mathrm{HNO}_{3} / \mathrm{HF} / 30 \% \mathrm{H}_{2} \mathrm{O}_{2}(5: 2: 1)$ using a microwave digester (Zhao et al., 2019). When the samples became colorless, the residues were diluted with $1 \% \mathrm{HNO}_{3}$ and the solutions were filtered by a $0.45 \mu \mathrm{m}$ membrane filter. Finally, the concentrations of Ni were analyzed by a flame atomic absorption spectrometer (AAS, nov AA400, Analytik Jena AG). It should be noted that the transfer factor of $\mathrm{Ni}$ from soil to wheat root $\left(\mathrm{TF}_{\text {soil to root }}\right)$ was calculated by the ratio of the 
total amount of $\mathrm{Ni}$ in the root to the soil (Sun et al., 2017). And, the transfer factor of Ni from root to shoot ( $\mathrm{TF}_{\text {root to shoot }}$ ) was calculated by the ratio of the total amount of $\mathrm{Ni}$ in the shoot to the root.

The bioavailability of $\mathrm{Ni}$ in the soil was extracted with $0.01 \mathrm{~mol} / \mathrm{L}$ of $\mathrm{CaCl}_{2}, 0.43 \mathrm{~mol} / \mathrm{L}$ of $\mathrm{HNO}_{3}$ and 0.05 $\mathrm{mol} / \mathrm{L}$ of EDTA solution (Wang et al., 2020; Lock and Janssen, 2010; Menzies et al., 2007). The specific steps were as follows: Freeze-dried soil samples $(1.0 \mathrm{~g})$ were weighed and then added $10 \mathrm{~mL}$ extractant respectively, shaken for 2 hours at room temperature. The centrifugation and filtration were conducted followed by using the AAS for the filterates (Rivera et al., 2016).

\subsection{Determination of biochemical parameters of wheat 2.4.1 Chlorophyll and proline contents}

We followed the method as previously reported in the literature to determine the chlorophyll content (Chandrasekhar et al., 2019). Pieces of fresh leaves of wheat along with $0.1 \mathrm{~g}$ of sample were poured into a mortar grinder, and $10 \mathrm{~mL}$ of $90 \%$ ethanol was added, then grounded in a dark environment until the tissue turned into white. All the homogenate was transferred to a centrifuge tube, and the supernatant was taken after the centrifugation. The absorbance values were respectively measured at $665 \mathrm{~nm}, 470$ $\mathrm{nm}$, and $649 \mathrm{~nm}$ to obtain the contents of chlorophyll a $\left(\mathrm{C}_{\mathrm{a}}\right)$, chlorophyll $\mathrm{b}\left(\mathrm{C}_{\mathrm{b}}\right)$, and xanthophyll $\left(\mathrm{C}_{\mathrm{x}, \mathrm{c}}\right)$, and then the total chlorophyll content was calculated. Moreover, the "ninhydrin method" (Bates et al., 1973) was applied to determine the free proline contents.

\subsubsection{TTC reduction content}

Dehydrogenase activity in the root could cause the TTC to decline. By measuring the TTC reduction content by a spectrophotometer at $485 \mathrm{~nm}$, dehydrogenase activity in the root of Ningmai 16 could be determined as described in a previous study (Zhao et al., 2010).

\subsubsection{MDA and GST contents}

Firstly, $10 \mathrm{~mL}$ of sodium phosphate buffer was poured into $1.0 \mathrm{~g}$ of root and shoot samples respectively followed by grounding to obtain the plant tissue homogenates. Then the supernatants (crude extracts of enzymes) were collected by centrifuging at $12000 \mathrm{rpm}$ for $20 \mathrm{~min}$ at $4^{\circ} \mathrm{C}$ and stored at $-80^{\circ} \mathrm{C}$. MDA and GST contents were determined by following the instructions of the matched test kit from Nanjing Jiancheng, China.

\subsection{Expression analysis of GST gene}

Gene expression of GST was determined by RT-qPCR (Zhao et al., 2019). Firstly, the root and shoot samples were grounded to the powder in a liquid nitrogen environment, then the total RNA was extracted according to the total RNA kit operating instructions. Secondly, the concentration and purity of RNA were determined by a Nanodrop spectrophotometer, and was used for first-strand cDNA synthesis. Thirdly, the RT-qPCR was performed by the specific primers. Actin gene was used as the internal reference gene. The primers of GST gene and related action gene are listed in Table S2 (Supplementary Material). 


\subsection{TEM observation}

The fresh shoots and roots were cut into 2-3 $\mathrm{mm}$ pieces, and quickly poured into $4 \%$ glutaraldehyde solution, then pumped and fixed in a refrigerator at $4^{\circ} \mathrm{C}$ for 24 hours. Then it was washed with $0.1 \mathrm{~mol} / \mathrm{L}$ of PBS, fixed for 4 hours with $1 \%$ hydrochloric acid solution, washed with distilled water for several times, and dehydrated by serial concentrations of ethanol (Chandrasekhar et al., 2019). Finally, EPON 812 epoxy resin was used for embedding, and limb V-type ultra-thin slicer was used for longitudinal cutting. The sections were stained with uranyl acetate and lead citrate, then were observed and photographed by using transmission electron microscope (JEM-1400Flash).

\subsection{Data analysis}

Microsoft Excel, IBM SPSS Statistics 25 and Origin 8.5 were used to process and analyze the data, presented as mean \pm standard deviation (SD). The significance of differences between the treatment and control groups were evaluated by a least significant difference (LSD) test and a one-way analysis of variance (ANOVA) at a significant level of $P<0.05$. Pearson correlation coefficient was used to conduct the correlation analyses of different extracted $\mathrm{Ni}$ and several physiological indicators.

\section{Results And Discussion}

\subsection{Ni content in the roots and shoots}

As displayed in Fig. 1, the roots showed higher Ni accumulation contents than shoots. During the entire incubation, the concentrations of $\mathrm{Ni}$ in both parts indicated a significantly increasing trend $(P<0.05)$ gradually with the Ni-spiked levels in soils. It revealed the obvious dose-response relationship, and the concentration range of Ni were: $88.26-6463.06 \mathrm{mg} / \mathrm{kg}$ for roots and $5.72-106.71 \mathrm{mg} / \mathrm{kg}$ for shoots (Fig. 1). The accumulation of $\mathrm{Ni}$ increased by over 73 folds in roots as much as that in control and over 18 folds in shoots. Specifically, in 1200-Ni groups, roots presented higher levels of Ni at $6463.06 \mathrm{mg} / \mathrm{kg}$, which was over 60 -fold higher than in the shoots $(106.71 \mathrm{mg} / \mathrm{kg})(\mathrm{Fig} .1)$.

TF can be used to characterize the absorption and migration of $\mathrm{Ni}$ in wheat, and it can also illustrate the differences of $\mathrm{Ni}$ uptake in roots and shoots in current conducted research study. $\mathrm{TF}_{\text {soil to root }}$ was always greater than 1.0, increasing continuously (Fig. 1), indicating that Ni was easily enriched in wheat roots. However, $\mathrm{TF}_{\text {root to shoot }}$ was observed to be far less than 0.1 , suggesting a significant decline with the Nispiked levels (Fig. 1). Some potential reasons could be used for interpretation the differences of $\mathrm{TF}_{\text {soil to }}$

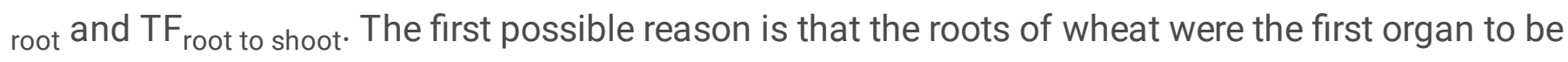
exposed to $\mathrm{Ni}$, which makes $\mathrm{TF}_{\text {soil to root }}$ was significantly higher than $\mathrm{TF}_{\text {root to shoot }}$. Additionally, the majority of pollutants could inhibit the roots' normal growth, and only small amounts of them could

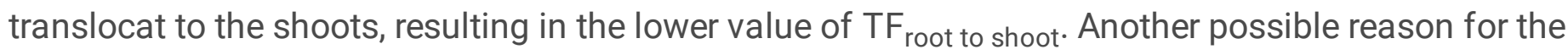
lower $\mathrm{TF}_{\text {root to shoot }}$ is that the occurrence of defense processes in roots such as protein chelation reducing the amount of $\mathrm{Ni}$ that can be transferred to the up-ground parts of wheat (Wang et al., 2004). 
Thirdly, the coordination of ligands produced in wheat could also lead to the differential distribution of $\mathrm{Ni}$ in roots and shoots, resulting in different TF values as proved in a published literature (Parlak and Kadiriye, 2016).

\subsection{Effect of Ni on biochemical parameters 3.2.1 Chlorophyll content}

The variations of total chlorophyll during the cultivation period are illustrated in Fig. 2(a), and the contents of chlorophyll a, chlorophyll b and carotenoid with respect to 45 days exposure are presented in Fig. $2 \mathrm{~b}$. The analyses of total chlorophyll did not reveal a significant variation before 30 days. On the 45 th day, the total chlorophyll were increased gradually and recorded the highest value at the Ni level of 200 $\mathrm{mg} / \mathrm{kg}$ then reduced significantly $(\mathrm{P}<0.05)$ after that (Fig. 2(a)). The appropriate concentration of Ni was beneficial to the hydrolysis of urea in leaves, which could improve the photosynthetic activity and promote the synthesis of chlorophyll. However, a significant inhibition $(P<0.05)$ was observed in wheat exposed to the highest Ni value of $1200 \mathrm{mg} / \mathrm{kg}$ (45 d) with reducing over $20 \%$ compared with the control (Fig. 2(a)). Overall it indicated the harmful impacts of Ni on wheat physiology, especially photosynthesis. The analyses of pigment contents at $45 \mathrm{~d}$ suggested the same pattern of chlorophyll a and total chlorophyll (Fig. 2(b)). Chlorophyll b and carotenoids reduced significantly $(P<0.05)$ only at high exposure levels of Ni. Among these three photosynthetic pigments, chlorophyll a was more susceptible to $\mathrm{Ni}$ stress, which were reinforced by a previous report about the impacts of nickel on canola plants (Kazemi et al., 2010).

Exposure to large amounts of heavy metals does interfere with the chlorophyll synthesis, adversely affecting the enzyme and photosynthetic activity (Chandrasekhar et al., 2019; Papi et al., 2002). The effects on photosynthesis have become a sophisticated process, because heavy metals often have different action sites in plants. Chlorophyll contents reduction might be due to lower iron contents, inhibiting the enzymes' activities related to chlorophyll biosynthesis, or may be due to the injury of plants' organs involved in photosynthesis under the Ni stress (Dhir et al., 2009; Chandrasekhar et al., 2019). The decrease of pigment contents can also be explained with respect to the displacement of magnesium ions by excessive Ni intake by plants (Parlak and Kadiriye, 2016; Padmaja et al., 1990).

\subsubsection{TTC reduction content}

Our current conducted research study revealed the dynamic changes of root vigor by measuring TTC reduction content (Fig. 2(c)). The root activity was found to decrease gradually with $\mathrm{Ni}$ exposure time from $10 \mathrm{~d}$ to $30 \mathrm{~d}$. On the 10th day, TTC reduction contents were not significantly affected except in the highest Ni-polluted group. On the 20th day, TTC reduction contents increased gradually and recorded the highest value at $400 \mathrm{mg} / \mathrm{kg}$ of $\mathrm{Ni}$ in soils, indicating the significant reduction $(P<0.05)$ with the increase of $\mathrm{Ni}$ exposure, and it was found to drop by $38 \%$ at $1200-\mathrm{Ni}$ level compared with the control. On the 30th day, the peak of TTC reduction value appeared at $100 \mathrm{mg} / \mathrm{kg}$ of $\mathrm{Ni}$, then exhibited a significant decline trend $(P<0.05)$ and kept stable $(\mathrm{Ni} \geq 200 \mathrm{mg} / \mathrm{kg})(\mathrm{Fig} .2(\mathrm{c}))$. This trend was in agreement with the 
previous phenomenon that $\mathrm{TF}_{\text {root to shoot }}$ rising first and then droping with the increase of Ni dose. As a rule of thumb, the root activity could directly affect the amounts of Ni transfer from root to shoot as inline our current findings in this study. According to Zhao's observations, the TTC reduction contents of maize were also presented a pattern of reducing first and then increasing (Zhao and Zhou, 2011).

\subsubsection{MDA and proline content}

MDA and proline contents in wheat roots and shoots are illustrated in Fig. 2(d) and (e). As shown in Fig. 2(d), on the 20th day, as the Ni dose was lower than $1200 \mathrm{mg} / \mathrm{kg}$, there was no significant change of MDA in wheat roots, and it was remarkably promoted at 1200-Ni treatment with a rising of 1.73-fold comparing with the control. As for shoots, a significant increase $(P<0.05)$ of MDA content was also depicted in the highest Ni values of the soil and recorded the $76.85 \%$ increment. A significant rising in the MDA values is a signal of membrane damage induced by excessive Ni contents (Rizwan et al., 2018). When exposure time of $\mathrm{Ni}$ was prolonged for 30 days, the levels of MDA showed a significant rising trend in shoots, while a notable decreasing trend in roots. And, the overall pattern of MDA contents in different treatments was similar to that for 20 days. Additionally, we found that shoots presented a more sensitive response to Ni exposure due to the high induced MDA concentration. Similarly, a higher MDA level was also reported in the shoots of Solanum nigrum L. rather than in the roots (Soares et al., 2016). According to Hayat et al. (2012), the high levels of $\mathrm{Ni}$ exposure could weaken the absorption of iron, copper, and zinc, etc by plants, and these nutrients played a significant role in the syntheses of MDA related enzymes.

As for roots, excess $\mathrm{Ni}(>400 \mathrm{mg} / \mathrm{kg}$ ) caused a significant increase in proline content, and recorded the value in the group of $1200 \mathrm{mg} / \mathrm{kg}$, which was 16.59-fold higher than that in the control (Fig. 2(e)). In root samples, the levels of proline increased first and then decreased with Ni-spiked concentrations, and reached the top value $(344.22 \mu \mathrm{g} / \mathrm{g})$ at $400 \mathrm{mg} / \mathrm{kg}$ of Ni, which was about 4 -fold higher than the control. Proline plays a vital role in free toxic-free radicals such as ROS, stabilizing membranes, enzymes protection and osmotic pressure regulation, thus the accumulation of proline could be regarded as another indicator for the stress of heavy metals (Ahmad et al., 2010; Jogaiah et al., 2013; Rasool et al., 2013). Similar observations of that the accumulation of proline were also found in cabbage (Pandey and Sharma, 2002), wheat (Siddiqui et al., 2011) and soybean (Kazemi et al., 2010) exposed to heavy metals.

\subsubsection{Soluble sugar}

Soluble sugar has a vital role in plant growth and stabilizing membranes, and also plays a significant role under the stress environment. It has been observed that there is no significant change of soluble sugar at low Ni-concentrations of soil, but the high treatments ( $\mathrm{Ni}>400 \mathrm{mg} / \mathrm{kg}$ ) exhibited a trend of significant increases $(\mathrm{P}<0.05)$ (Fig. 2(f)). Specially, both in the groups of 800-Ni and 1200-Ni, the levels of soluble sugar increased by more than $30 \%$ compared with the control (Fig. 2(f)). Numerous studies have confirmed that soluble sugar could also be induced to increase significantly under high temperature, high salt and drought conditions (Asensi-Fabado et al., 2015; Irenaeus et al., 2014).

\subsection{GST content and gene expression under the Ni stress}


GST enzyme has a vital role in resisting heavy metals stress (Nkongolo et al., 2018). The impacts of Ni exposure on GST activity of wheat roots and shoots are illustrated in Fig. 3. The activity of GST in shoots was significantly induced when exposed to Ni-800 and Ni-1200 (Fig. 3(a)). However, the low activity of GST in roots was depicted in all Ni-spiked groups compared with the control (Fig. 3(b)), indicating a certain hysteresis. There are two possible reasons to explain the phenomenon of GST activity induced in roots under the $\mathrm{Ni}$ stress. The first reason is that after being exposed to $\mathrm{Ni}$, the defense mechanism of roots was first activated, and a large amount of GST could be consumed to remove reactive oxygen species and other secondary products. The second reason is that the roots, as the preferred organ to feel the stimulation of $\mathrm{Ni}$ in soils, accumulated too many toxic free radicals, which directly impacted the synthesis of GST (Zhao et al., 2019). It has also been reported that the activity of GST was markedly enhanced when plants were exposed to nickel, cadmium or herbicides (Ahammed et al., 2013; Saleh et al., 2020). Khan et al. (2012) found that under high concentrations of $\mathrm{Ni}$ exposure, plants could produce excessive $\mathrm{H}_{2} \mathrm{O}_{2}$ or $\mathrm{O}^{2-}$, which would be transformed into highly toxic free radicals followed by the induction of more GST. GST could bind to them, separate from vacuoles or transfer to exosomes, thus protecting the plants from the damage of ROS.

As shown in Fig. 3, a decreasing trend of relative expression of GST gene was observed firstly both in shoots and roots, then increased with the rising of Ni dosage. Additionally, we used pearson correlation analysis to predict the relationship between GST activity and GST gene expression. The results revealed that there was a highly significant correlation between the GST content and the related gene expression $\left(R^{2}=0.909, P<0.01\right)$, indicating that the variation of GST concentrations caused by the changes of GSTrelated gene expression under the Ni stress. The toxicity of Ni on GST in wheat could be concluded that the GST gene expression exhibited a clear downward trend first, and this inhibition was obviously relieved at a high dosage (Ni-1200). The promotion of GST gene expression increased the contents of GST, and then enhanced the tolerance of wheat to Ni stress. Moreover, the potential mechanisms could be proposed as following: When exposed to high Ni-contaminated soil, antioxidant enzymes in wheat were not sufficient to clear free radicals, leading to oxidative stress, which further induced the expression of GST gene as discussed in the literature (Nkongolo et al., 2018).

\subsection{Anatomical change}

The intracellular changes induced by Ni both in the shoot and root cells of wheat were analyzed by TEM (Fig. 4). TEM micrographs of the control shoot samples revealed a well-defined cell structure, regular organization of cell wall, proper orientation of several chloroplasts, intact mitochondria, nucleus and large central limpid vacuoles (Fig. $4(a, b, c)$ ). Numerous grana and 1 or 2 large starch granules were observed to be distributed regularly in the chloroplasts (Fig. $4(a, b, c))$. The prominent cytological alterations were found in shoot cells after treating with $\mathrm{Ni}(\mathrm{Fig} .4(\mathrm{~d}, \mathrm{e}, \mathrm{f}))$. The cell wall was distorted along with thickeness in shape. Irregular outline of chloroplasts could be clearly observed, and it had lost their typical organization: Thylakoid membranes, grana, and starch granules were rarely visible. Vesicles and cytoplasmic vacuoles were more easily formed in the cells. Additionally, the cell wall, cell membrane, as 
well as the cytoplasm were often more electron dense than the control, and metal particles could be found to aggregate in the shoot cells.

On the cross section of the control root, the epidermal cells were arranged regularly and tightly, the cell membrane was close to the cell wall, and the cytoplasm was evenly distributed (Fig. 4 (g,h,i)). The cortical cells had large vacuoles and intercellular spaces. After treating with $\mathrm{Ni}$, the thickened and distorted cell wall and irregular cell outline could be clearly observed (Fig. $4(\mathrm{j}, \mathrm{k}, \mathrm{l})$ ). The cytoplasm was contracted markedly and numerous vesicles or cytoplasmic vacuoles formed inside the cell. According to TEM micrographs of the roots, it was also observed that the electron dense bodies of metal particles clustered in the cell wall, cell membrane, cytoplasm and intercellular space (Fig. $4(\mathrm{j}, \mathrm{k}, \mathrm{I})$ ).

Ultrastructural analyses of wheat shoots and roots revealed that the intracellular variation occurred under the Ni stress, the translocation of Ni particles in wheat. It elucidated the wheat detoxification mechanism of $\mathrm{Ni}$ from another perspective, such as the cell-wall thickening, vacuole compartmentation, and so on (Chandrasekhar et al., 2019; Chandra et al., 2010). According to these anatomical changes, all our findings are considered as more convincing. It was believed that excessive Ni exposure could impact the osmotic function of wheat cells, and destroy their cell structures and organelles. It indicated that the activity reduction in roots followed by significant changes in biochemical parameters including pigment content, enzyme activity and related gene expression. The accumulation of $\mathrm{Ni}$ in Eclipta prostrata (L.) was conducted by Chandrasekhar et al. (2019), but there was no noticeable changes in cell organelles or membranes by TEM observation. It could be concluded that the plant has high tolerance to Ni stress. More severe ultrastructural damages were observed in Sardo and Siciliano when they were exposed to the soil of $\mathrm{Pb}$ and $\mathrm{Cd}$ co-existed (Sorrentino et al., 2018). In addition, numerous literatures have also revealed the morphological changes of plants' root caused by heavy metals, such as $\mathrm{Cd}, \mathrm{Pb}$, and $\mathrm{Cu}$ (Sorrentino et al., 2018, Chandra et al., 2010).

\subsection{Ni bioavailability in different extracting agents}

The harmfulness and transformation ability of $\mathrm{Ni}$ in the process are closely related to its actual chemical forms or combinative forms. Actually, the bioavailability of $\mathrm{Ni}$ in soils is considered to be more easily absorbed as well as more harmful to plants. In this study, we had used three extracting agents, i.e., 0.01 $\mathrm{M} \mathrm{CaCl}_{2}, 0.05 \mathrm{M} \mathrm{EDTA}$ and $0.43 \mathrm{M} \mathrm{HNO}_{3}$ (Fig. 5). The pattern of bioavailability of Ni was extracted by the three reagents, and the extracted $\mathrm{Ni}$ was observed to be in a concentration-dependent manner. Among these three extractants, their extraction capacity were observed by the following trend: $\mathrm{HNO}_{3}>$ EDTA > $\mathrm{CaCl}_{2}$ (Fig. 5). The bioavailable content per unit $\mathrm{Ni}$ concentration extracted by $\mathrm{CaCl}_{2}$ increased with the Nispiked dose, and improved from $0.734-1.824 \%$, which was just opposite to the trend of using the other two extractants (Fig. 5). Usually, $\mathrm{CaCl}_{2}$ has been used to extract the water-soluble and the exchangeable $\mathrm{Ni}$, while $\mathrm{HNO}_{3}$ and EDTA could extract various forms of $\mathrm{Ni}$. It has been observed as the complex transformation of $\mathrm{Ni}$ in soils such as precipitation and dissolution, thus the different extraction results were appeared (Baklrcioglu et al., 2011; Wang et al., 2020). 
As shown in Table 1, pearson correlation was selected to predict the relationship between the changes of biochemical parameters of wheat and the bioavailable contents of $\mathrm{Ni}$ in soils. It has been found that the accumulation of $\mathrm{Ni}$ in wheat (shoots and roots), the content of proline (root), MDA (shoot and root), soluble sugar and GST (shoot and root) exhibited a strong significant positive correlation with the bioavailable $\mathrm{Ni}$ extracted by $\mathrm{HNO}_{3}, \mathrm{EDTA}$, and $\mathrm{CaCl}_{2}(P<0.01)$. The contents of MDA and GST in roots, and chlorophyll in shoots indicated a good negative relationship with the extracted $\mathrm{Ni}$ by $\mathrm{HNO}_{3}$ and EDTA $(P<0.05)$. These correlations suggested that the series of oxidative stress reactions produced in wheat were mainly due to the absorption of available $\mathrm{Ni}$ in soils, resulting in the changes of various biochemical indexes. In another sense, these changes could be suitable biological indicators using to predict the bioavailability of $\mathrm{Ni}$ in a soil-wheat system.

Table 1

Correlation analysis between physiological indicators of wheat and the bioavailable $\mathrm{Ni}$ in soil.

\begin{tabular}{|c|c|c|c|}
\hline & $\mathrm{Ni}-\mathrm{CaCl}_{2}$ & Ni-EDTA & $\mathrm{Ni}-\mathrm{HNO}_{3}$ \\
\hline Ni-shoots & $0.944^{\star \star}$ & $0.970^{\star \star}$ & $0.984^{* *}$ \\
\hline Ni-roots & $0.968^{\star \star}$ & $0.963^{\star \star}$ & $0.981^{* *}$ \\
\hline MDA-roots & 0.523 & $0.602^{*}$ & $0.598^{*}$ \\
\hline MDA-shoots & $0.836^{* *}$ & $0.721^{\star \star}$ & $0.719^{* *}$ \\
\hline Proline contents & $0.975^{\star \star}$ & $0.916^{* *}$ & $0.915^{\star \star}$ \\
\hline Chorophyll & $-0.688^{*}$ & $-0.595^{*}$ & $-0.640^{\star}$ \\
\hline Soluble sugar & $0.851^{* \star}$ & $0.897^{* \star}$ & $0.912^{\star \star}$ \\
\hline GST-shoots & $0.960^{\star *}$ & $0.891^{\star \star}$ & $0.892^{* \star}$ \\
\hline GST-roots & -0.619 & $-0.715^{\star}$ & $-0.660^{*}$ \\
\hline
\end{tabular}

However, no clear correlation was observed among the contents of MDA (root), GST (root) and the $\mathrm{CaCl}_{2}{ }^{-}$ extracted $\mathrm{Ni}$. In many literatures, $\mathrm{CaCl}_{2}$ extraction was often supposed to be the best way for evaluating heavy metals' bioavailability in soils, especially its bioavailability in plants (Menzies et al., 2007; Lock and Janssen, 2010). Our findings revealed that the bioavailability of Ni extracted by EDTA and HCl could be well correlated with the physiological indexes of wheat, and even better than that extracted by $\mathrm{CaCl}_{2}$ for some indexes including MDA (root), GST (root), and soluble sugar (Fig. 5). Stable complexes could be formed between EDTA extractants and soil heavy metals, which is considered to reflect the interactions between heavy metals and plant root exudates (Menzies et al., 2007). Leleyter et al. (2012) reported that the bioavailability of $\mathrm{Pb}, \mathrm{Cu}$, and $\mathrm{Zn}$ in soils could be well evaluated by EDTA extractants. For acidic 
extractants such as HCL, many researchers believe that it is not an ideal choice due to the poor correlations between the accumulation of heavy metals in plants and their acid extracted amounts (Menzies et al., 2007). However, Kubová et al. (2008) has claimed that the acid extractants could also be used to evaluate the bioavailability of heavy metals in soils as inline our current findings.

\section{Conclusions}

To the best of our knowledge, the occurrence, physiological impacts and toxicity of nickel in Ningmai 16 have been investigated systematically for the first time. Our explored findings showed that there was a significant dose-response relationship between the spiked $\mathrm{Ni}$ in soils and the accumulation of $\mathrm{Ni}$ in wheat shoots and roots. The variations of wheat parameters such as cholorophyll, TTC reduction content, proline, soluble sugar, MDA, and GST, as well as TEM observations proved the toxicity of $\mathrm{Ni}$ to wheat. Some of biological indicators (proline, MDA, GST, soluble sugar) are helpful to predict the bioavailability of $\mathrm{Ni}$ in soils. Furthermore, we probed the potential detoxification mechanisms in wheat under the oxidative damage induced by $\mathrm{Ni}$, such as regulating the metabolite content, inducing the expression of related genes, cell-wall thickening, vacuole compartmentation, and the depth of mechanisms into gene levels. However, we only explored the impacts of GST gene expression on GST levels in our current research work. We believe that further studies will be conducted to investigate some other physiological and biochemical indicators' related gene expression, such as proline, antioxidant enzymes by using our developed route.

\section{Declarations}

\section{Acknowledgements}

This research was supported by the projects of the National Key Research and Development Program of China (2018YFC1800600, 2019YFC1805200); the National Natural Science Foundation of China (21737005, 41877124).

- Ethical Approval: Not applicable

- Consent to Participate: Yes

- Consent to Publish: Yes

- Authors Contributions

Gehui Wang: Writing-Original draft preparation, Conceptualization, Methodology

Muhammad Tariq: Writing-Reviewing and Editing

Fang Liu: Visualization, Investigation

Qinran Xiao: Data curation, Investigation, Writing- Reviewing and Editing 
Cheng Peng: Writing- Reviewing and Editing

Wei Zhang: Supervision, Validation

Jie Yang: Supervision, Writing-Reviewing and Editing

- Funding

The National Key Research and Development Program of China (2018YFC1800600, 2019YFC1805200); the National Natural Science Foundation of China $(21737005,41877124)$

- Competing Interests

The authors declare that there is no conflict of interest.

- Availability of data and materials: Yes

\section{References}

1. Ahammed GJ, Choudhary SP, Chen S, Xia X, Shi K, Zhou Y, Yu J (2013) Role of brassinosteroids in alleviation of phenanthrenecadmium co-contamination-induced photosynthetic inhibition and oxidative stress in tomato. J Exp Bot 64:199-213

2. Ali H, Khan E, Sajad MA (2013) Phytoremediation of heavy metals-concepts and applications. Chemosphere 91:869-881

3. Asensi-Fabado MA, Ammon A, Sonnewald U, Munne-Bosch S, Voll LM (2015) Tocopherol deficiency reduces sucrose export from salt-stressed potato leaves independently of oxidative stress and symplastic obstruction by callose. J Exp Bot 3:957-971

4. Ahmad P, Jaleel CA, Salem MA, Nabi G, Sharma S (2010) Roles of enzymatic and nonenzymatic antioxidants in plants during abiotic stress. Crit Rev Biotechnol 30:161-175

5. Bates LS, Waldren RP, Teare ID (1973) Rapid determination of free proline for water-stress studies. Plant Soil 39:205-207

6. Baklrcioglu D, Kurtulus YB, Jbar H (2011) Comparison of extraction procedures for assessing soil metal bioavailability of to wheat grains. Clean- Soil Air Water 39:728-734

7. Chandrasekhar C, Ray JG (2019) Nickel accumulation, localisation and the biochemical responses in Eclipta prostrata (L.). J Soil Contam 28:81-100

8. Chen C, Huang D, Liu J (2010) Functions and toxicity of nickel in plants: Recent advances and future prospects. Clean - Soil Air Water 37:304-313

9. Chandra R, Yadav S (2010) Potential of typha angustifolia for phytoremediation of heavy metals from aqueous solution of phenol and melanoidin. Ecol Eng 36:1277-1284

10. Dhir B, Sharmila P, Saradhi PP, Abdul S (2009) Physiological and antioxidant responses of Salvinia natans exposed to chromium-rich wastewater. Ecotoxicol Environ Saf 72:1790-1797 
11. Hayat S, Khalique G, Irfan M, Wani AS, Tripathi BN, Ahmad A (2012) Physiological changes induced by chromium stress in plants: An overview. Protoplasma 249:599-611

12. He MD, Xu SC, Lu YH, Li L, Zhong M, Zhang YW, Wang Y, Li M, Yang J, Zhang GB (2011) L-carnitine protects against nickel-induced neurotoxicity by maintaining mitochondrial function in Neuro-2a cells. Toxicol Appl Pharm 253:38-44

13. Irenaeus KST, Mitra SK (2014) Understanding the pollen and ovule characters and fruit set of fruit crops in relation to temperature and genotype - A review. J Appl Bot Food Qual 87:157-167

14. Jogaiah S, Govind SR, Tran LS (2013) Systems biology-based approaches toward understanding drought tolerance in food crops. Crit Rev Biotechnol 33:23-39

15. Kazemi N, Khavari-Nejad RA, Fahimi H, Saadatmand S, Nejad-Sattari T (2010) Effects of exogenous salicylic acid and nitric oxide on lipid peroxidation and antioxidant enzyme activities in leaves of Brassica napus L. under nickel stress. Sci Hort 126:402-407

16. Khan NA, Anjum NA, Ahmad I, Pacheco M, Prasad MNV, Duarte AC, Ahmad A, Umar S, Iqbal M, Pereira E, Mohmood I (2012) Modulation of glutathione and its related enzymes in plants' responses to toxic metals and metalloids-A review. Environ Exp Bot 75:307-324

17. Kubová J, Matús P, Bujdos M, Hagarova I, Medved' J (2008) Utilization of optimized BCR three-step sequential and dilute $\mathrm{HCl}$ single extraction procedures for soil-plant metal transfer predictions in contaminated lands. Talanta 75:1110-1122

18. Lock K, Janssen CR (2010) Influence of aging on copper bioavailability in soil. Environ Toxicol Chem 22:1162-1166

19. Leleyter L, Rousseau C, Biree L, Baraud F (2012) Comparison of EDTA, HCl and sequential extraction procedures, for selected metals $(\mathrm{Cu}, \mathrm{Mn}, \mathrm{Pb}, \mathrm{Zn})$, in soil, riverine and marine sediments. J Geochem Explor 116:51-59

20. Menzies NW, Donn MJ, Kopittke PM (2007) Evaluation of extractants for estimation of the phytoavailable trace metals in soil. Environ Pollut 145:121-130

21. Nkongolo K, Theriault G, Michael P (2018) Nickel-induced global gene expressions in red maple (Acer rubrum): Effect of nickel concentrations. Plant Gene 14:29-36

22. Norouzi S, Khademi H, Cano AF, Acosta JA (2015) Using plane tree leaves for biomonitoring of dust borne heavy metals: A case study from Isfahan, Central Iran. Ecol Indic 57:64-73

23. Padmaja K, Prasad DDK, Prasad ARK (1990) Inhibition of chlorophyll synthesis in Phaseolus vulgaris seedlings by cadmium acetate. Photosynthetica 24:399-405

24. Pandey N, Sharma CP (2002) Effect of heavy metals $\mathrm{Co}^{2+}, \mathrm{Ni}^{2+}$ and $\mathrm{Cd}^{2+}$ on growth and metabolism of cabbage. Plan Sci 163:753-758

25. Papi M, Sabatini S, Altamura MM, Hennig L, Scha“fer E, Costantino P, Vittorioso P (2002) Inactivation of the phloem-specific Dof zinc finger gene DAG1 affects response to light and integrity of the testa of arabidopsis seeds. Plant Physiol 128:411-417 
26. Parlak U, Kadiriye (2016) Effect of nickel on growth and biochemical characteristics of wheat (Triticum aestivum L.) seedlings. NJAS-Wagen. J Life Sc 76:1-5

27. Rasool S, Siddiqi TO, Ahmad P (2013) Changes in growth, lipid peroxidation and some key antioxidant enzymes in chickpea genotypes under salt stress. Acta Physiol Plant 35:1039-1050

28. Rivera MB, Giráldez MI, Fernández-Caliani JC (2016) Assessing the environmental availability of heavy metals in geogenically contaminated soils of the Sierra de Aracena Natural Park (SW Spain). Is there a health risk? Sci. Total Environ 560:254-265

29. Rizwan M, Mostofa MG, Ahmad MZ, Imtiaz M, Tu S (2018) Nitric oxide induces rice tolerance to excessive nickel by regulating nickel uptake, reactive oxygen species detoxification and defenserelated gene expression. Chemosphere 191:23-25

30. Sun LJ, Yang JJ, Fang HX, Xu C, Peng C, Huang HM, Liu LL, Duan DC, Zhang XZ, Shi JY (2017) Mechanism study of sulfur fertilization mediating copper translocation and biotransformation in rice (Oryza sativa L.) plants. Environ Pollut 226:426-434

31. Saleh SR, Kandeel MM, Ghareeb D, Ghoneim TM, Talha NI, Alaoui-Sossé B, Aleya L, Abdel-Daim MM (2020) Wheat biological responses to stress caused by cadmium, nickel and lead. Sci Total Environ 706:136013-136023

32. Seregin IV, Kozhevnikova AD (2006) Physiological role of nickel and its toxic effects on higher plants. Russ J Plant Physi 53:257-277

33. Shaw CJ, Withers MA, Lupski JR (2004) Uncommon deletions of the smith-magenis syndrome region can be recurrent when alternate low-copy repeats act as homologous recombination substrates. Am J Hum Genet 75:75-81

34. Siddiqui MH, Al-Whaibi MH, Basalah MO (2011) Interactive effect of calcium and gibberellin on nickel tolerance in relation to antioxidant systems in Triticum aestivum L.. Protoplasma 248:503511

35. Soares C, Sousa AD, Pinto A, Azenha M, Teixeira J, Azevedo RA, Fidalgo F (2016) Effect of 24epibrassinolide on ROS content, antioxidant system, lipid peroxidation and Ni uptake in Solanum nigrum L. under the Ni stress. Environ Exp Bot 122:115-125

36. Sorrentino MC, Capozzi F, Amitrano C, Giordano S, Arena C, Spagnuolo V (2018) Performance of three cardoon cultivars in an industrial heavy metal-contaminated soil effects on morphology, cytology and photosynthesis. Plant Physiol Bioch 351:131-137

37. Wang GH, Xia XQ, Yang J, Tariq M, Zhao J, Zhang M (2020) Exploring the bioavailability of nickel in a soil system: Physiological and histopathological toxicity study to the earthworms (Eisenia fetida). J Hazard Mater 383:121169-121179

38. Wang XP, Shan XQ, Zhang SZ, Wen B (2004) A model for evaluation of the phytoavailability of trace elements to vegetables under the field conditions. Chemosphere 55:811-822

39. Xia XQ, Lin SY, Zhang W, Lin KF, Lu Q, Zhou BS (2018) Toxic responses of microorganisms to nickel exposure in farmland soil in the presence of earthworm (Eisenia fetida). Chemosphere 192,43-50 
40. Yang XQ, Zhang YL (2015) Characterization of glutathione S-transferases from Sus scrofa, Cydia pomonella and Triticum aestivum: Their responses to cantharidin. Enzyme Microb Tech 69:1-9

41. Zhao J, Lu C, Tariq M, Xiao Q, Zhang W, Huang K, Lu Q, Lin K, Liu Z (2019) The response and tolerance mechanisms of lettuce (Lactuca sativa $L$.) exposed to nickel in a spiked soil system. Chemosphere 222:399-406

42. Zheng LP, Wang GQ, Long T, Lin YS, Feng YH, Zhang Y, Zhao X (2018) A study of risk-based ecological soil screening levels among different countries and its implication for China. Asian $\mathrm{J}$ Ecotoxic 13:39-49. (in Chinese)

43. Zhao PF, Zhu YH, Wang W (2010) Evaluation and improvement of spectrophotometric assays of TTC reduction: Maize (Zea mays) embryo as an example. Acta Physiol Plant 32:815-819

44. Zhao N, Zhou M (2011) Effect of nickel stress on root growth and membrane protection system of maize seedlings. J Agr Sci 39:5821-5823

\section{Figures}
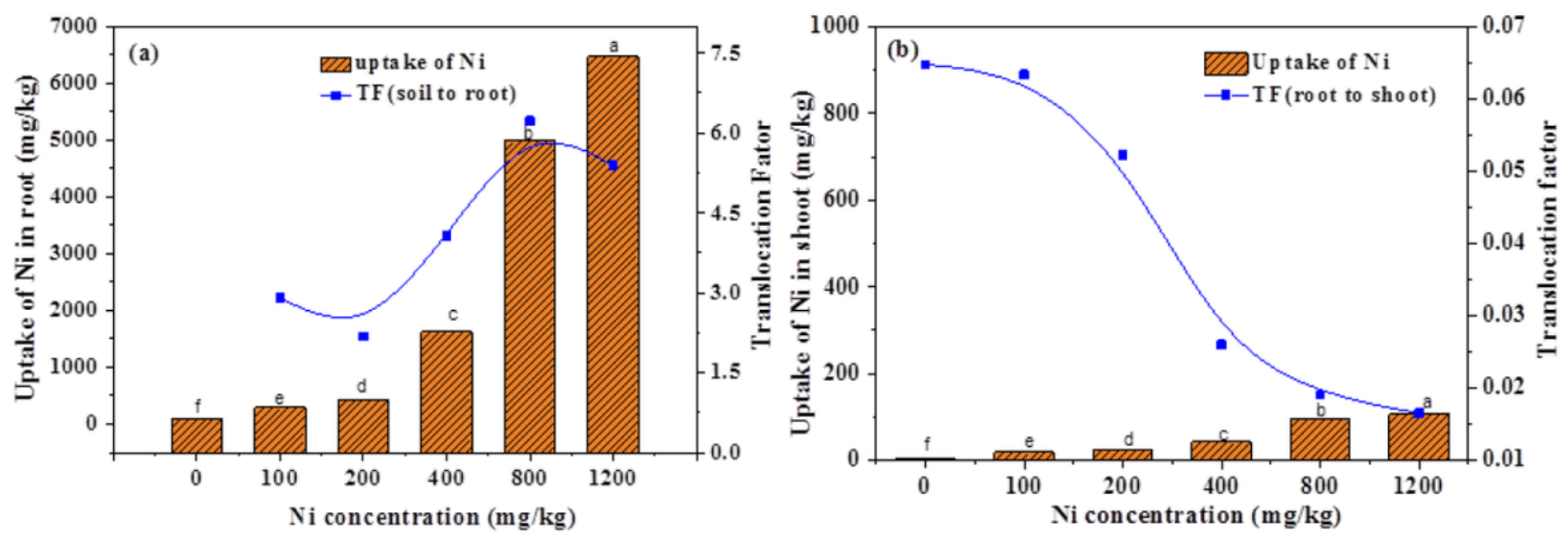

Figure 1

Accumulation and migration of $\mathrm{Ni}$ in wheat treated with different $\mathrm{Ni}$ concentrations. Replicates $(\mathrm{n})=3$. 

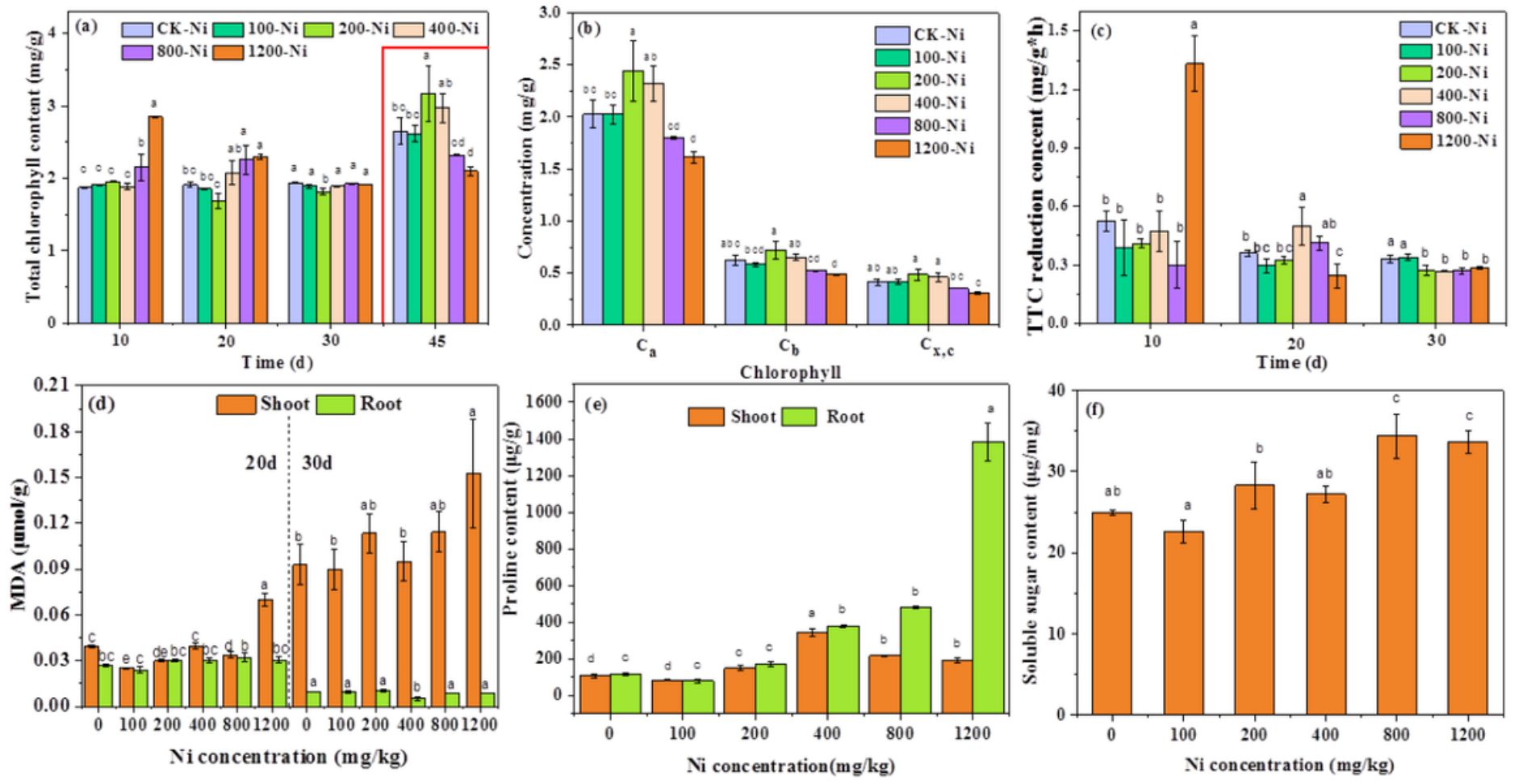

Figure 2

Physiological responses of wheat to nickel stress. (a) Total chlorophyll contents, (b) chlorophyll a, chlorophyll b, carotenoids contents, (c) TTC reduction contents, (d) MDA contents, (e) proline contents, (f) soluble sugar contents. Different lowercase letter indicates significant differences $(P<0.05)$ between different Ni-treated groups. Replicates $(n)=3$.
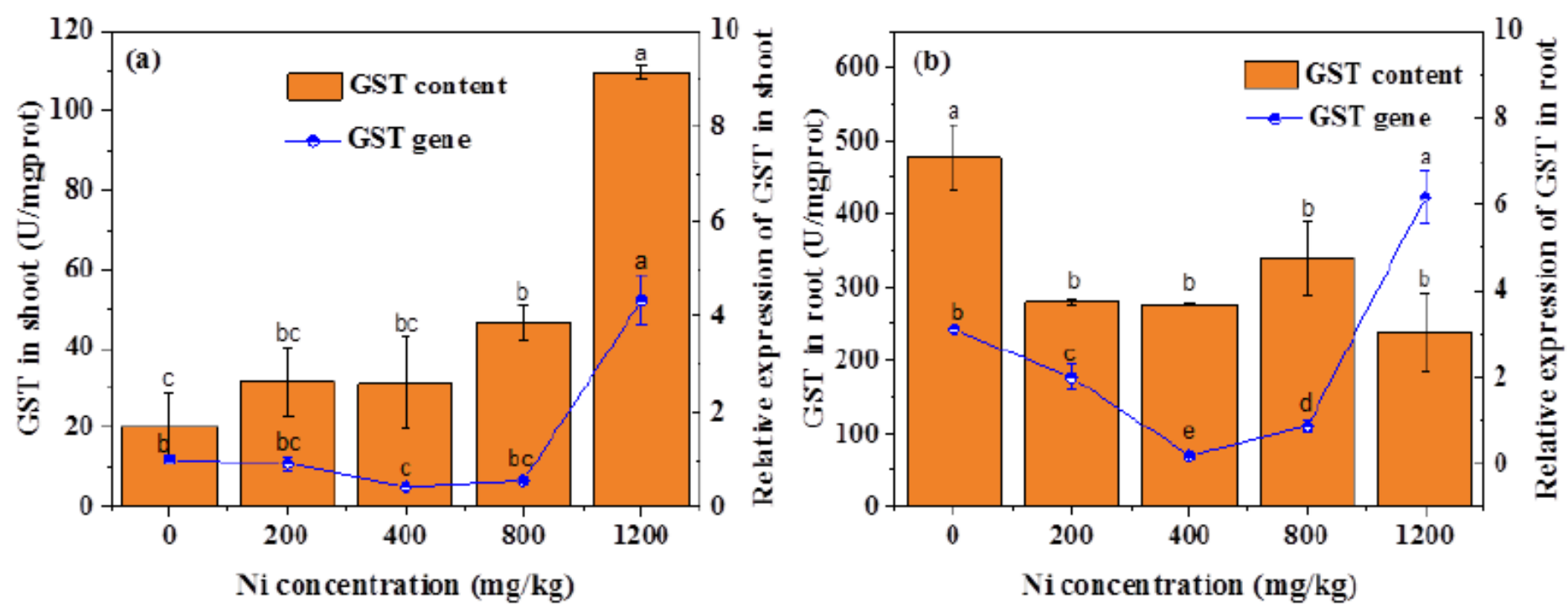

Figure 3 
GST activity and related GST gene expression in wheat shoots and roots. (a) in shoots, (b) in roots. Different lowercase letter indicates significant differences $(P<0.05)$ between different Ni-treated groups. Replicates $(n)=3$.
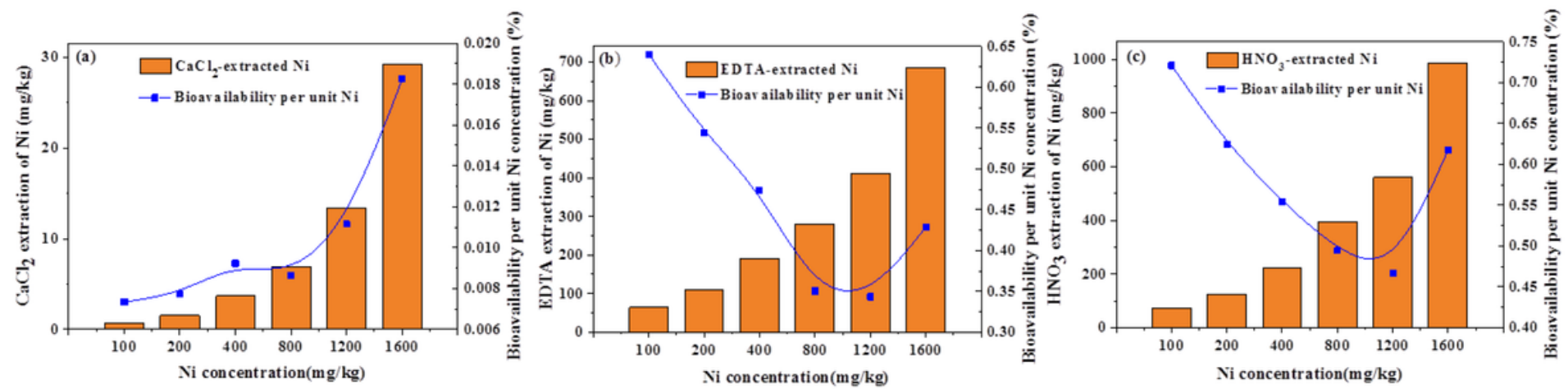

\section{Figure 4}

Bioavailable Ni extracted by the three extractants. (a) $0.01 \mathrm{M} \mathrm{CaCl}$, (b) $0.05 \mathrm{M}$ EDTA, and (c) $0.43 \mathrm{M}$ HNO3 in soil and the bioavailability per unit Ni concentration. Replicates $(n)=3$. 

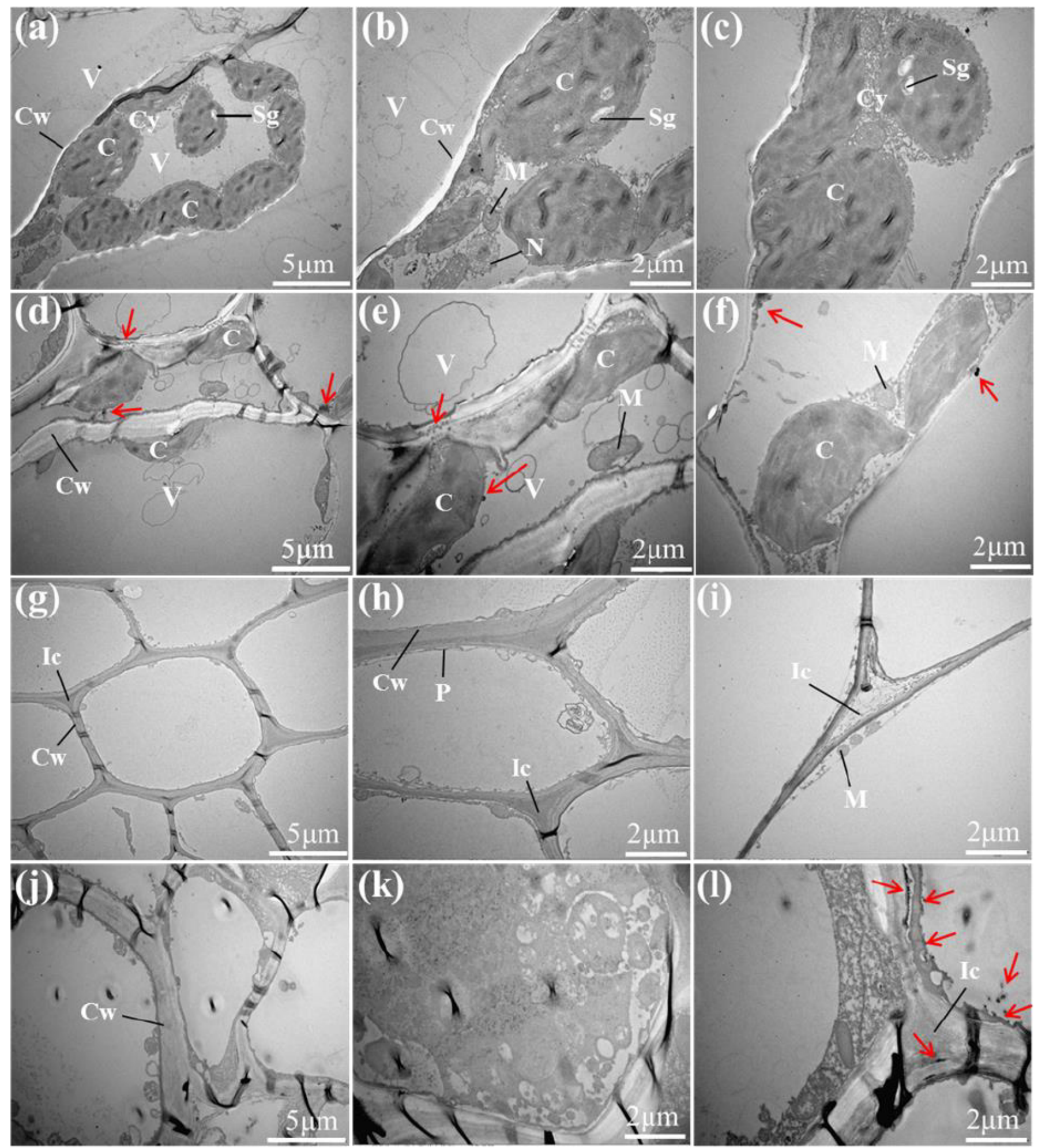

\section{Figure 5}

TEM electron micrographs of wheat shoots (a-f) and roots $(\mathrm{g}-\mathrm{l})$ of Ningmai 16 exposed to 0 and 1200 $\mathrm{mg} / \mathrm{kg}$ of Ni. Control (a-C; g-i); Ni treatment (d-h; j-l). Starch grains (Sg); Cell wall (Cw); Cytoplasm (Cy); Vacuole (V); Mitochondria (M); Chloroplast (C); Cell nucleus (N); Plasmalemma (P); Intercellular space (IC). The arrows indicate the cluster of electron dense particles of metals inside the cell. 


\section{Supplementary Files}

This is a list of supplementary files associated with this preprint. Click to download.

- SupplementaryMaterial.doc 